\title{
A VARIETY OF PARAMYOTONIA CONGENITA
}

\author{
BY
}

\author{
E. B. FRENCH and R. KILPATRICK \\ From the Eastern General Hospital, Edinburgh
}

Paramyotonia congenita was first described by Eulenberg (1886). It is a rare, hereditary disorder of muscle in which severe loss of power is induced by degrees of cooling which are insufficient to affect normal muscle. Myotonia also appears on cooling. However, the paralysis produced by cooling distinguishes paramyotonia from Thomsen's disease. The weakness and myotonia can easily be produced under controlled conditions so that the disease lends itself to investigation. In spite of this fact, few observations have been made and nothing is known about the fundamental defect. The present case of a man aged 51 years is of particular interest because of certain additional features, and a personal and family history of generalized attacks of weakness such as occur in familial periodic paralysis. The case history is presented in full and is followed by some observations on the induction and relief of paralysis and myotonia.

\section{Case Report}

Personal History.-Myotonia has been present since infancy, for it was noted that his eyes did not open normally after a fit of crying. As long as he can remember he has suffered from a combination of myotonia and weakness on exposure to cold. The condition was general or local according to the extent of the cooling. Thus 10 minutes in a swimming pool made him helpless; he could not work off the effects by exercise and his movements were weak as well as stiff. At school in the winter time he found it difficult to write or to stand up suddenly. If he was warmly clad but his face was cooled, he found that after smiling or sneezing his face would remain contorted, and he used to cover his face with a handkerchief on such occasions to avoid social embarrassment. In the summer, as a youth, he took a leading part in amateur wrestling, but he was unable to do so in winter. He believes that the symptoms induced by cold are less severe now than when he was a child. He still finds difficulty in speaking in cold weather, and dysphagia results from drinking cold liquids. Chewing is also affected, sometimes by inability to relax after a bite, at other times by weakness which he overcomes by pushing up his jaw with his hands. He states that myotonia passes off when he warms up, but that weakness persists for some hours. Irrespective of temperature he has at all times been able to produce myotonia of the eyelids by shutting them tightly for several seconds.

He describes about 12 attacks of paralysis resembling familial periodic paralysis, which occurred when he was between 8 and 20 years of age. Most of the attacks were present on awakening. In some an arm, a leg, or both legs only were paralysed, in others all four limbs, the trunk, and the neck were involved. He could always talk, eat, and empty his bowels and bladder normally. Paralysis lasted for two or three days, during which time he had to be fed, and complete recovery occurred within a week. Because of one of these attacks he was sent home from a scout camp with a diagnosis of poliomyelitis. The usual precipitating factor was exercise during the previous evening. When paralysis was incomplete, he could work it off by exercising the part affected. Attacks occurred at all seasons of the year, and he recalls one attack occurring in day time after sunbathing.

In November, 1949, he attended with persistent weakness of the right leg and some wasting of the calf. In August, 1950, he complained of difficulty in climbingo stairs and in rising from a chair. In October, 1951, bothlegs were weak, and wasting was present in both calves. From then until the present time there has been progressive wasting of the legs and of the lower halves of the thighs. He is now apt to trip over irregularities of the ground and he is unable to rise again without assistance.

Family History.-A genealogical tree of the family is shown in Fig. 1. The information for this was given by the patient, and none of the other members has been examined. All the living members are strikingly uncooperative and would not permit even an interview to elicit a medical history. This reluctance was previously shown by the patient, as his condition escaped notice while he was in hospital in June, 1949, suffering from pneumonia. The patient is only certain about the presence or absence of myotonia in the family, and thus only this abnormality is included. In addition some have weakness induced by cold, but he is uncertain about its presence or absence in others. His grandfather (II.2) was found to have contracture of the calf muscles when he was admitted to hospital for some other condition, and bilateral tenotomy was performed. One maternal aunt (III.5) also developed wasting of various muscles, in addition to life-long myotonia and weakness on cooling. The inheritance of the myotonia is clearly due to autosomal dominance, as has been previously noted 


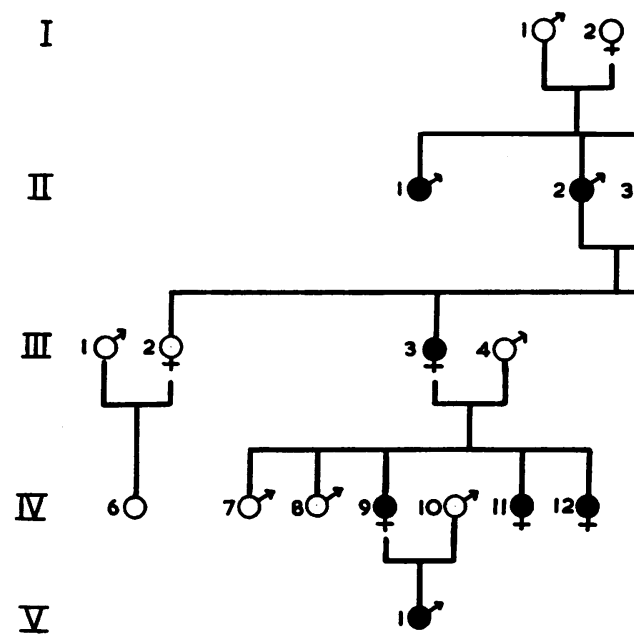

Fig. 1.-Genealogical tree showing inheritance of myotonia by autosomal dominance.

(Thomasen, 1948). However, in rare instances, Thomasen found recessive inheritance. Various factors, such as minimal symptoms, memory, legitimacy, or mutation may account for the recorded absence of myotonia in either of the two great grandparents.

Physical Examination.-The muscular development of the upper part of the body contrasted with the wasting of the legs. The front half of the scalp was bald and there was a patch of occipital baldness, which was not unreasonable for his age. Pubic and axillary hair were normal, and hair was present on the chest, arms, and legs. Both testes were very small. The breasts were normal and the thyroid gland was not enlarged. The cardiovascular system and an electrocardiogram were normal. Renal function was unimpaired. The daily urinary excretion of $17-$ ketosteroids was $14.0 \mathrm{mg}$. and of 17 -hydroxycorticosteroids was $6.7 \mathrm{mg}$. Estimation of gonadotrophic hormone excretion in urine was also normal for his age.

His intellectual functions and sensory examination were normal. Ophthalmological examination was kindly performed by Dr. G. I. Scott and he found no cataract or disturbance of vision. After strong contraction of the orbicularis oculi had been maintained for several seconds the patient was unable to open his eyelids. This delay in relaxation passed off gradually in about two minutes. It persisted even with repetitive contractions. The clavicular heads of both sternomastoid muscles were moderately wasted and there was slight weakness of forward flexion of the head.

Upper Limbs.-No wasting was evident, but the flexor muscles of the right forearm were abnormally firm and there was shortening, as he was unable to extend the interphalangeal joints when the wrist was dorsiflexed.
Power of all movements was reduced, particularly of the distal muscles. His grip, measured by the method described later, was less than half of that of several male students. Muscle tone was normal. The tendon jerks were very feeble.

Trunk.-The power of flexion was good, but extension was impaired. The abdominal reflexes were absent.

Legs.-There was bilateral pes cavus. When the patient stood upright with the feet together, the heels were $4 \mathrm{~cm}$. from the ground, due to wasting, hardening, and shortening of the calf muscles. The anterior tibial groups were slightly wasted. There was atrophy of the lower half of the quadriceps muscle on each side, particularly of the vastus medialis. Tone in the muscles unaffected by fibrosis was normal. Knee and ankle jerks were absent; plantar responses were flexor.

Electrical Excitation.-Several of the affected muscles were tested by use of the Ritchie-Sneath stimulator. Some reaction of degeneration was present, such as has been recorded previously in cases of dystrophia myotonica, and after cooling there were changes characteristic of myotonia (Brain, 1955).

\section{Efiect of Various Procedures in Measuring Weakness and Myotonia}

Power of Grip.-Power of grip was measured by asking the patient to squeeze a rubber bulb with maximum force for two seconds. The force was transmitted through rubber pressure tubing to a tambour on which was sealed a lever which recorded on a kymograph. A side-arm opening in the tubing, which was only closed for each contraction, gave a constant base line even when the bulb was held in cold or hot water. The response of the patient to the abrupt commands-" grip ", " relax"- 
with two seconds between them gave a smooth curve and a remarkably constant response. Deflection upwards denoted gripping and deflection downwards denoted relaxation. The system was calibrated against a mercury manometer and over the range of power shown by the patient the height of the response bore a linear relationship to the pressure within the bulb. The rate of fall of the curve after the command " relax" gave a clear indication of myotonia, but an accurate measure of the degree of myotonia was impossible when weakness was severe. Room temperature for all observations was $20^{\circ} \mathrm{C}$. A satisfactory method was evolved for recording flexion of the ring finger in response to stimulation of the ulnar nerve of a normal person. When this was applied to the patient his base line weakness was such that scarcely any movement of the finger could be seen and no movement of the recording system could be obtained on maximal stimulation of the ulnar nerve. Changes in muscle temperature produced by immersion in cold or hot water were measured by a thermistor soldered in the tip of an intramuscular needle. This was calibrated before each measurement by immersion in water at a known temperature.

Local Cooling.--One forearm was cooled in water whilst the rest of the body was kept warm; the grip of the cooled arm was affected by weakness and myotonia; the grip of the other arm was unaffected. The rate of onset and the intensity of the effects were greater as the temperature of the water was reduced. Weakening occurred at $28^{\circ} \mathrm{C}$., but it was slow in onset and slight in degree.

Prolonged Forearm Cooling at $12.5 \mathrm{C}$ : Recovery in Air at $20^{\circ}$ C.- For subsequent observations on cooling a temperature of $12.5^{\circ} \mathrm{C}$. was selected as it produced little discomfort and a conveniently rapid onset of paralysis. Either forearm was immersed in water in a large sink, and the temperature was kept approximately constant with no stirring by floating a few pieces of ice in the water.

Paralysis was nearly complete after 40 minutes' cooling.
The rubber bulb placed in the weakened hand could be retained only with difficulty. Recovery at room temperaure was incompltete after several hours.

Prolonged Forearm Cooling: Recovery in Water at $40^{\circ} \mathrm{C}$.- This was studied in the patient and two groups of controls.

Patient.-After 38 minutes in water at $12.5^{\circ} \mathrm{C}$. the arm was plunged into hot water at $40^{\circ} \mathrm{C}$. The grip became weaker for the first five to 15 minutes in hot water, and then power returned gradually to its initial value after warming for 25 minutes. However, the severe myotonia produced by the cooling passed off within four minutes of transferring to hot water, at a time when power was still diminishing (Fig. 2).

Two Normal Males.-Cooling at $12 \cdot 5^{\circ} \mathrm{C}$. for 40 minutes did not cause any change in power which could be measured by the method employed. If, however, the forearm of a normal subject was immersed in water at $9^{\circ} \mathrm{C}$., measurable weakness of grip and difficulty in relaxation developed in 20 minutes. Power was reduced to $53 \%$ after one hour, and four minutes after transferring to hot water was $88 \%$ of normal power.

Two Male Patients with Dystrophia Myotonica.-No weakness was detected after cooling for 40 minutes at $12 \cdot 5^{\circ} \mathrm{C}$.

Ischaemia.-Occlusion of the patient's brachial arteryọ by a cuff at $200 \mathrm{~mm}$. Hg with the arm in water at $35^{\circ} \mathrm{C} . \mathbb{\Phi} \rightarrow$ resulted in paralysis in 20 minutes. Release of the cuff $\sigma$ was followed by complete recovery in three minutes. $\frac{\mathbb{D}}{0}$ This was comparable with a normal person.

Cooling of Ischaemic Arm at $12 \cdot 5^{\circ} \mathrm{C}$. for Five Minutes:

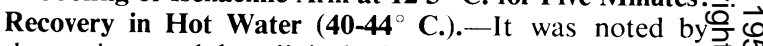
the patient and by clinical observation that when the $F$ circulation was released after cooling the ischaemic forearm for five to 10 minutes at $12 \cdot 5^{\circ} \mathrm{C}$. there was less disability than when a free circulation was present throughout. The difference was more obvious if blood was expressed from the arm by an Esmarch bandage

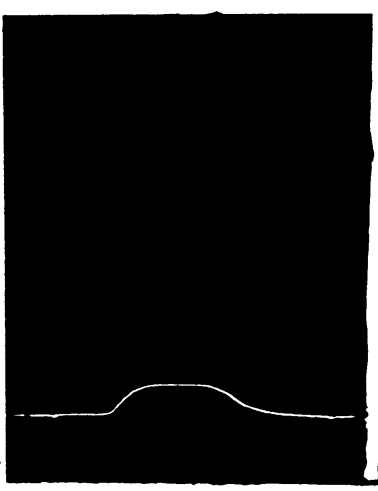

(a)

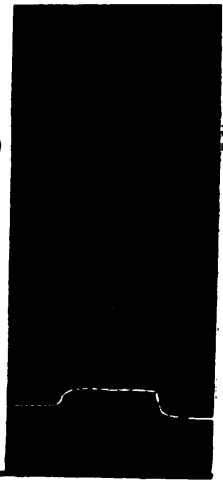

(b)

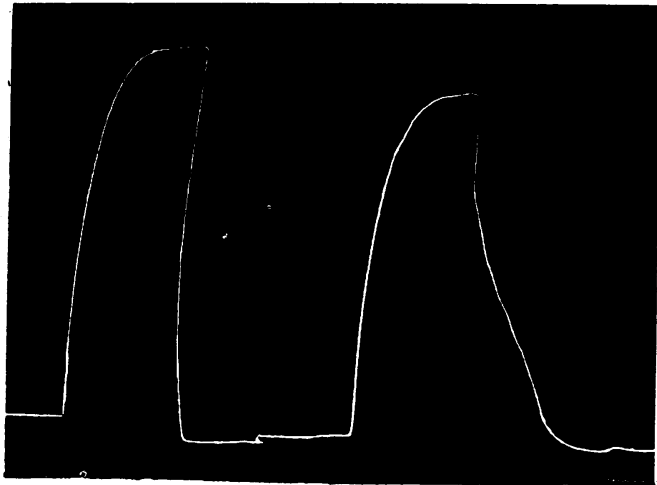

(c) (d)

FIG. 2.-(a) Grip after $38 \mathrm{~min}$. in water at $13^{\circ} \mathrm{C}$. showing myotonia and weakness. (b) Grip 14 min. after subsequent transfer into water at $39^{\circ} \mathrm{C}$. Myotonia has passed off: weakness still present. (c) Patient's normal grip. (d) Grip takeı $1.5 \mathrm{~min}$. after immersion of ischaemic arm in water at $12.5^{\circ} \mathrm{C}$. for five min., showing myotonia and slight weakness. 
TABLE

EFFECT OF ISCHAEMIA ON WEAKNESS PRODUCED BY 5 MINUTES' COOLING IN WATER AT $12.5^{\circ} \mathrm{C}$. AND RECOVERY IN WATER AT $40^{\circ} \mathrm{C}$.

\begin{tabular}{|c|c|c|c|c|c|c|}
\hline & $\begin{array}{l}\text { Number of } \\
\text { Observations }\end{array}$ & $\begin{array}{c}\text { Power of Grip } \\
\text { before Cooling } \\
\text { as Height in } \\
\text { Centimetres } \\
\text { Range }\end{array}$ & $\begin{array}{c}\text { Mean Power of } \\
\text { Grip 1 Minute } \\
\text { after Cooling } \\
\text { (\% Control } \\
\text { Reading } \pm \text { S.E.) }\end{array}$ & $\begin{array}{c}\text { Mean Power of } \\
\text { Grip } 6 \text { Minutes } \\
\text { after Cooling } \\
\text { (\% Control } \\
\text { Reading } \pm \text { S.E.) }\end{array}$ & $\begin{array}{l}\text { Mean Power of } \\
\text { Grip } 11 \text { Minutes } \\
\text { after Cooling } \\
\text { ( } \% \text { Control } \\
\text { Reading } \pm \text { S.E.) }\end{array}$ & $\begin{array}{l}\text { Mean Power of } \\
\text { Grip } 16 \text { Minutes } \\
\text { after Cooling } \\
\text { (\% Control } \\
\text { Reading } \pm \text { S.E.) }\end{array}$ \\
\hline $\begin{array}{l}\text { Arm with circulation intact } \\
\text { during cooling } \\
\text { Arm with circulation oc- } \\
\text { cluded during cooling }\end{array}$ & $\begin{array}{l}8 \\
3\end{array}$ & $\begin{array}{l}2 \cdot 9-4 \cdot 3 \\
2 \cdot 3-3 \cdot 3\end{array}$ & $\begin{array}{l}78 \pm 5 \cdot 5 \\
88 \pm 13 \cdot 3\end{array}$ & $\begin{array}{r}72 \pm 6 \cdot 7 \\
101 \pm 7 \cdot 1\end{array}$ & $\begin{array}{r}73 \pm 5 \cdot 2 \\
111 \pm 8 \cdot 6\end{array}$ & $\begin{array}{r}77 \pm 4 \cdot 2 \\
113 \pm 8 \cdot 8\end{array}$ \\
\hline
\end{tabular}

before cooling. Cooling for five minutes was the optimum time for bringing out this difference and no weakness due to ischaemia without cooling occurred in so short a period. Both because the resulting difference in power might be attributable to reactive hyperaemia and in order to prevent further cooling, the arm was plunged into hot water as the ischaemia was released. The results are compared with the opposite arm treated similarly except for the ischaemia (Fig. 2) and are shown in the Table.

With the circulation intact, the power decreased slightly after cessation of cooling and going into hot water. However, using approximate test of significance (difference between means compared with $1.5 \times$ sum of standard errors of means) this further fall is not significant. Mean power is greater at all times after cooling with the circulation occluded. However, using the above test, only the differences at six, 11 , and 16 minutes after cooling are statistically significant. Thus the ischaemic arm still develops slight weakness after cooling, but has returned to normal six minutes after cooling, whereas the non-ischaemic arm is still weak after the 16 minutes.

The effect of ischaemia on the weakness caused by cooling might result from differences in the degree or the rate of cooling or rewarming. These possibilities were studied using the forearm of a normal subject.

Muscle Temperature during Cooling and Reheating in a Normal Subject.-The arm was cooled at $12.5^{\circ} \mathrm{C}$. for five minutes and then heated in water at 40 to $44^{\circ} \mathrm{C}$. as described above. Muscle temperature was measured at various depths in the midline of the flexor muscle mass of the forearm, $3 \mathrm{~cm}$. below the elbow.

At a depth of $2 \mathrm{~cm}$. the average fall in temperature was $0.75^{\circ} \mathrm{C}$. ( 20 observations). After plunging the arm into hot water the temperature remained steady or fell a little further during the next four minutes and then began to rise to the original level after a further four to six minutes. At this depth heat is evidently lost to the colder superficial layers at a greater rate than it is supplied by the blood.

Measurements made at a depth of $1 \cdot 2 \mathrm{~cm}$. showed an average fall in temperature of $2 \cdot 6^{\circ} \mathrm{C}$. (four observations). After transferring the arm to hot water the temperature began to rise within one minute, returning to the original level in five minutes and rising $1.5^{\circ} \mathrm{C}$. above it in the next five minutes.

There was no difference between the ischaemic and the unoccluded arms. It seems clear, therefore, that a rise in temperature due to reactive hyperaemia in muscle in these circumstances is negligible.
Fatigue.-Fatigue of the grip was induced by making maximum voluntary contractions of the rubber bulb once per second, and taking a record every minute. In both patient and normal subjects power was reduced by one half after six minutes. Some improvement in power occurred after one minute's rest, but the return to normal power was slow and was incomplete after 25 minutes. No difference between the patient and normal subjects was found in these tests.

Chemical Constituents of the Blood after Cooling.These were measured generally and locally.

General Cooling.-The patient was immersed up to the neck in a bath at $21^{\circ} \mathrm{C}$. for 10 minutes, after which the arms, legs, and trunk were so weakened that it was necessary for two people to lift him out of the bath and assist him to bed. For the first hour after removal from the bath, the weakness became even greater. After immersion there was no change in the serum potassium level or an E.C.G.

Forearm Cooling.-Blood was obtained from the median cubital vein immediately before and after cooling one forearm for 20 minutes and at the same time from the uncooled arm. There was no change in the blood glucose, plasma phosphorus, serum sodium, potassium, and creatine levels in the blood from either arm.

Effect of Drugs upon the Patient.-Glucose, adrenaline, neostigmine, quinine, and potassium chloride were thus tested.

Glucose.-A dose of $50 \mathrm{~g}$. was given but no subjective or objective change in power took place over the next three hours.

Adrenaline.-A subcutaneous injection of $0.6 \mathrm{mg}$. adrenaline was followed by a slight increase in power after 10 minutes, which was sustained for 20 minutes.

Adrenaline did not prevent or diminish the weakening effect of cooling.

Neostigmine.-A subcutaneous injection of $2 \mathrm{mg}$. neostigmine was followed after 25 minutes by generalized myotonia. The patient dared not swallow, for previous experience had taught him that his breathing would become obstructed. He sat with his head forward, with saliva dripping from his mouth and saying little, and that in a low, husky voice. One grip was recorded which showed myotonia but no weakness. It cannot be said that no decrease in power would have occurred subsequently for his distress made it imperative to terminate 


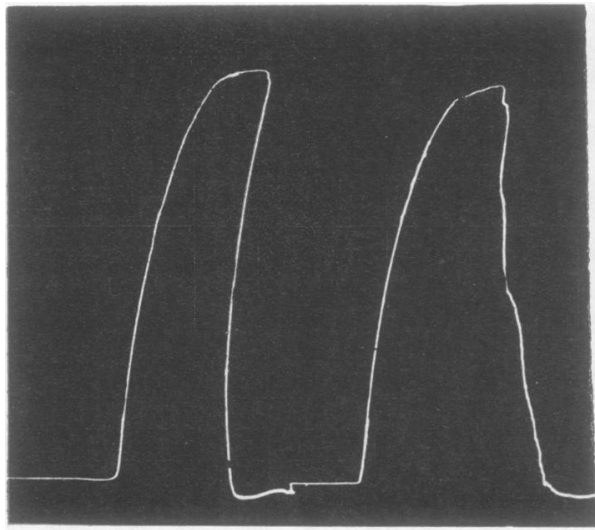

(a)

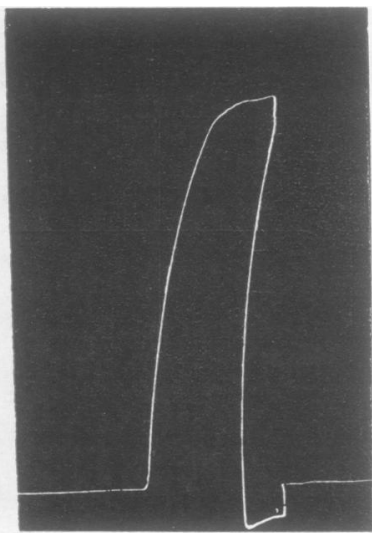

(c)

Fig. 3.-Atropine sulphate, $1 \mathrm{mg}$. subcutaneously; neostigmine, $2 \mathrm{mg}$. subcutaneously $10 \mathrm{~min}$. later: (a) $17 \mathrm{~min}$. after neostigmine; grip still normal; (b) 32 min., myotonia present showing step-like relaxation phase; power normal; (c) $42 \mathrm{~min}$., normal grip a few minutes after $0.5 \mathrm{~g}$. quinine hydrochloride intravenously.

two and a half hours later when he was very weak. The patient was greatly alarmed by this effect and though he had been very cooperative throughout a period of five years he was unwilling to undergo further trials of potassium chloride. Potassium balance studies were not made owing to the lack of suitable facilities. It might be thought that the apparent effect of potassium chloride was hysterical in origin. Clinical observation convinced us that this was not the case. In addition, the recovery of power was steady over a period of hours, the patient $\mathbb{D}$ being placed in such a position that he could not see the $\frac{O}{\mathbb{D}}$ height of each previous record. Moreover, attempts to를 record submaximal grips invariably resulted in an irregur $\bar{D}$ lar upper limit of the curve quite unlike the smooth type of curve recorded in the figures. Irregularity of relaxationo in the presence of myotonia was often recorded and is a feature which has been noted by others (Ravin, 1939). It is therefore beyond all reasonable doubt that the ob-? served effect of potassium was genuine.

Cortisone.-In view of the ill effects of potassium, it was thought that cortisone might improve his condition. In addition, Shy and McEachern (1951) have reported improvement of senile myopathy by cortisone. He was given cortisone acetate, $200 \mathrm{mg}$. daily by mouth, increased at any time. The serum potassium $5 \cdot 2 \mathrm{~m}$.Eq./1. before the dose was given and $5 \cdot 0 \mathrm{~m} . \mathrm{Eq} . / \mathrm{l}$.

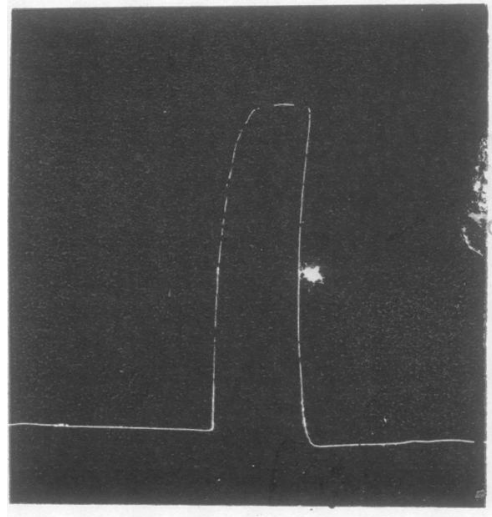

(a)

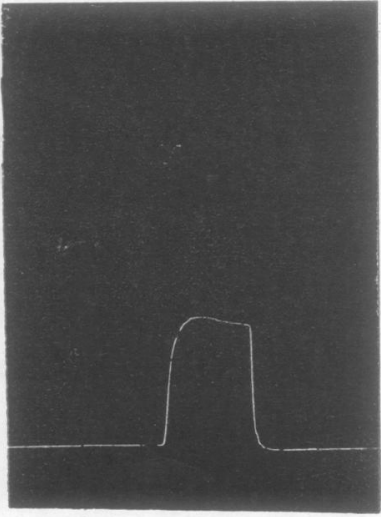

(b)
FIG. 4.- (a) Normal grip before $5 \mathrm{~g}$. potassium chloride orally. (b) Same arm $2 \cdot 5$ hours later. showing weakness but no myotonia. 
for three days, diminishing to $12.5 \mathrm{mg}$. on the tenth day, up to a total of $1 \mathrm{~g}$. There was no objective improvement in power or the reaction to cooling. Later he took $25 \mathrm{mg}$. cortisone daily for two months and was enthusiastic about the results at first. However, there was no improvement in his grip and at the end of the course he did not return for further supplies as he was putting on too much weight.

\section{Discussion}

The hereditary disorder from which this man suffers has some of the features of dystrophia myotonica. There is myotonia, muscle wasting, testicular atrophy, and frontal baldness. There is, however, no sign of cataract in spite of his age, no myopathic facies, and there is not a striking atrophy of the sternomastoid muscles.

The attacks of paralysis during childhood and adolescence suggest familial periodic paralysis. Muscular atrophy has been recorded late in the course of this disease (Biemond and Daniels, 1934). Both glucose and adrenaline failed to precipitate an attack of paralysis, but the patient was not having clinical attacks at the time of investigation. The effect of potassium was tried in the hope that the weakness might be improved or that paralysis in response to cold might be prevented. Instead of improvement a prolonged attack of generalized weakness developed after $5 \mathrm{~g}$. of potassium chloride. Myotonia was not aggravated, though Russell and Stedman (1936) produced severe myotonia in a case of Thomsen's disease by oral administration of $5 \mathrm{~g}$. potassium chloride. Kolb, Harvey, and Whitehill (1938) could not demonstrate any effect of potassium on the myotonia in dystrophia myotonica. Muscular paralysis associated with low, or more rarely, with high levels of serum potassium is well known. Thus an attack in a patient subject to periodic paralysis is usually accompanied by a transfer of potassium to the intracellular phase and a fall in the serum concentration. However, there is a poor correlation between the onset and the severity of the attacks and the magnitude of the depression of the serum potassium level (Talbott, 1941). There have been occasional reports of a clinical syndrome resembling periodic paralysis in which no change in the serum potassium level occurred during attacks. In one such family, oral potassium chloride caused a vague lack of well-being and did not prevent attacks, so that all the patients discontinued the treatment after a few weeks (Tyler, Stephens, Gunn, and Perkoff, 1951). By contrast, in other conditions such as diabetic coma under treatment with insulin, the concentration of potassium in the serum may fall to levels far below those commonly found during an attack of periodic paralysis, and yet paralysis does not commonly occur. In these circumstances the cellular content of potassium is also lowered. There are a number of case records in the literature showing close similarity with various features of the present case, but we can find no previous record of paralysis being caused by a therapeutic dose of potassium such as that employed in the present case.

The features shown by this patient are similar to those described by Eulenburg (1886). He recorded the muscle disorder inherited as a dominant character without sex-linked inheritance, which he named paramyotonia congenita. Almost all the muscles became stiff and weak after prolonged cooling and did not regain normal power for several hours, even after rewarming. Generalized attacks of weakness also riccurred but always in response to cold. He comp $\because d$ the condition with familial periodic paralusis.' He could not demonstrate active or mech. Illv induced myotonia. However, certain musc ved spontaneous tonic contraction when coolea $r$ ample, these patients experienced tonic contracticins of the orbicularis oculi and oris when exposed a a cold wind. Schott (1935) investigated a patient with paramyotonia. When warm, muscle function was normal; on cooling, irritability increased as in Eulenburg's family, but at the same time active myotonia appeared; after prolonged cooling he claimed that myotonia gradually decreased as paresis increased. Thus we would classify the present case as a variety of paramyotonia. The dissimilarities are that some myotonia-is always present, and that generalized attacks of weakness, which were not apparently related to cold, had previously occurred.

Weakness from local cooling has also been reported in familial periodic paralysis. Zabriskie and Frantz (1932) reported the effect of cooling of the forearm in a young man suffering from a clinical syndrome resembling familial periodic paralysis. After 12 minutes in water between $10^{\circ}$ and $14^{\circ} \mathrm{C}$. it was noted tha relaxation of the flexors of the fingers after voluntary contraction was distinctly slow. After 35 minutes paralysis was practically complete and recovery was incomplete 12 hours later. Heating the paralysed limb in water at $40^{\circ} \mathrm{C}$. restored normal power in one ho ir. Similar observations are reported by Bickerstaff (153). McArdle (1956) reports that local cooling produced gross local weakness in periodic paralysis, which was not due to local lowering of serum potassium. This is further evidence against the primary disorder being a defect in potassium metabolism.

The coincidence of various rare features in the one patient and the occurrence of several of them in many other members of the family supports the view that myotonia congenita, dystrophia myotonica, and paramyotonia congenita are variants of the same 
hereditary defect (Maas and Paterson, 1950; Stevens, 1954). The features also suggest a relationship to periodic paralysis, where the primary defect is probably in voluntary muscle.

The patient's history suggests that the myotonia and the weakness usually appear together, and this is certainly true in response to cooling. Our observations enabled us to separate these two features. It has been mentioned that weakness with no demonstrable myotonia followed the ingestion of $5 \mathrm{~g}$. potassium chloride; unfortunately we were unable to find a rapid method of relieving the weakness produced. Myotonia was precipitated by neostigmine and abolished by quinine, but no weakness occurred. Warming of the cooled arm relieved the myotonia in a few minutes, during which time the weakness did not improve or actually become greater.

The rate of onset and recovery from paralysis due to anoxia of the forearm was normal. The recovery from weakness produced by cold was more rapid in the arm which was ischaemic during the cooling. This suggested that during cooling some substance might diffuse from the muscles into the blood or vice versa. However, we failed to detect any difference in several chemical constituents in blood taken from the cooled arm compared with the uncooled arm.

\section{Summary}

A man aged 51 years presented with a history of myotonia aggravated by cold, of weakness induced by cold, of attacks during his youth resembling familial periodic paralysis, and of progressive weakness and wasting of the muscles of his legs since the age of
45 years. The family history showed inheritance of myotonia as an autosomal dominant characteristic.

Investigation revealed the following features:(1) Immersion in a cold bath caused general weakness and myotonia. Cooling of a forearm induced local paralysis and myotonia. Power only recovered after many hours at room temperature or about one hour in hot water. Myotonia passed off in a few minutes in hot water. (2) Ischaemia during cooling hastened the rate of recovery on rewarming. (3) Neostigmine caused myotonia, but no weakness. Quinine prevented and relieved myotonia. (4) Potassium chloride taken orally rapidly produced weakness.

The authors would like to express their thanks to Dr. J. A. Loraine for the estimation of urinary gonadotrophin, to Dr. S. L. Tompsett for the chemical analyses, and to Dr. R. Alexander for the loan of the thermistor.

Bickerstaff, E. R. (1953). Journal of Neurology, Neurosurgery and Psychiatry, 16, 178.

Biemond A., and Daniels, A. P. (1934). Brain 57, 91.

Brain, W. Russell (1955), Diseases of the Nervous System, 5th ed. Oxford University Press, London.

Eulenburg, A. (1886). Neurol. Zbl., 5, 265.

Kolb, L. C., Harvey, A. M., and Whitehill, M. R. (1938), Bull Johns Hopk. Hosp., 62, 188

Maas, O., and Paterson, A. S. (1950). Brain, 73, 318.

McArdle, B. (1956). Brit. med. Bull., 12, 226.

Marshall, J (1952) Journal of Neurology, Neurosurgery and Psychiatry, 15, 206.

Ravin, A. (1939). Medicine (Baltimore), 18, 443.

Russell, W. R., and Stedman, E. (1936). Lancet, 2, 742.

Schott, E. (1935). Dtsch. Arch. klin. Med., 178, 255.

Shy, G. M., and McEachern, D. (1951). Journal of Neurology, atry, 14, 101.

Stevens, J. R. (1954).A.M.A. Arch. Neurol, Psychiat., 72, 726.

Talbott, J. H. (1941). Medicine (Baltimore), 20, 85.

Thomasen, E. (1948). Myotoni: Thomsen's Disease. forlaget, Aarhus.

Tyler, F. H., Stephens, F. E., Gunn, F. D., and Perkoff, G. T. (1951) J. clin. Invest., 30, 492. Zabriskie, E. G., and Frantz, A. M. (1932). Bull. neurol. inst. N.Y. 